\title{
Excessive faecal losses of vitamin A (retinol) in cystic fibrosis
}

\author{
F Ahmed, J Ellis, J Murphy, S Wootton, A A Jackson
}

\begin{abstract}
Vitamin A (retinol) deficiency is a recognised complication of cystic fibrosis and is presumed to be a consequence of an impairment in the digestion and absorption of dietary fats. The dietary intake of fat and retinol was assessed from a seven day weighed food intake in 11 subjects with cystic fibrosis and 12 matched controls. Faecal excretion of retinol and fat were measured from three day stool collections. There was little difference between the two groups in the intake of fat or retinol equivalents. When studied the subjects with cystic fibrosis were clinically stable and the apparent absorption of fat was not significantly different to that in the controls. There was a significant increase in the faecal losses of retinol in cystic fibrosis, which was unrelated to the degree of fat in the stool. In cystic fibrosis the median retinol recovered in the stool was $40 \%$ of the intake, compared with $1.8 \%$ in the controls. It is concluded that there is a specific defect in the handling of retinol by the gastrointestinal tract in cystic fibrosis, which may be unrelated to the digestion and absorption of dietary fat.
\end{abstract}

Children with cystic fibrosis experience complex nutritional problems caused by a combination of the underlying disease process and the effects of pancreatic exocrine insufficiency upon digestion and absorption. There is clinical evidence for deficiencies of the fat soluble vitamins, and xerophthalmia has been attributed to vitamin A (retinol) deficiency. ${ }^{12}$

A recognised feature of cystic fibrosis is steatorrhoea caused by a failure of fat digestion and absorption. In earlier studies it was thought most likely that a deficiency of retinol was a consequence of fat malabsorption. ${ }^{1}$ Postmortem studies have shown that the retinol concentration in the liver might be three to four times that seen in a control group, however, even though serum concentrations of vitamin A might be low. ${ }^{3}$ Supplementation with retinol failed to bring the serum concentrations within the normal range, despite normal concentrations in the liver. ${ }^{4}$ These observations gave rise to the suggestion that the primary disorder of retinol metabolism in cystic fibrosis might be an inability to mobilise retinol from storage in the liver. ${ }^{4}$ Under normal circumstances retinol is carried in the circulation bound to retinol binding protein, which is synthesised in the liver. There is evidence to show that factors which influence the synthesis or mobilisation of retinol binding

protein may contribute to a clinical deficiency of retinol. Among the possible factors that could contribute to a deficiency are hepatic damage, ${ }^{4}$ zinc deficiency, ${ }^{5}$ and protein inanition. ${ }^{6}$

Notwithstanding these observations, little work has been carried out to explore the original suggestion by Andersen that deranged gastrointestinal handling of retinol is of importance. ${ }^{1}$ As the intestinal esterification of retinol appears to be normal, ${ }^{7}$ it has been presumed that any fat maldigestion and malabsorption due to pancreatic insufficiency would automatically be associated with increased faecal loss of the vitamin. To our knowledge no attempt has been made to quantitate faecal losses. Animal experiments suggest that under normal circumstances retinol is excreted in urine or stool as a series of complex degradation products, but mainly as the glucuronide. ${ }^{8}$ Therefore, it is reasonable to assume that any retinol found in the stool approximates malabsorbed losses, rather than endogenous wastage or excretion.

In this study we have developed a method for measuring retinol in the stool by high performance liquid chromatography (HPLC). Using this method we have been able to demonstrate an apparent excess faecal loss of retinol relative to fat in children with cystic fibrosis compared with a control group.

\section{Subjects and methods}

SUBJECTS

The study was carried out in 11 subjects who were participating in a larger study of nutritional state in cystic fibrosis. They were compared with a group of age matched local children and young adults, who were willing to participate and had no relevant medical history. The study had the approval of the joint ethical subcommittee of the Southampton and South West Hampshire district health authority and the University of Southampton. Consent was given by the subjects or the parents of the children in the full knowledge that they could withdraw at any time without prejudice. All the subjects showed some degree of failure to thrive, but were generally well at the time of study. They all had regular access to dietary support and had regular supplements of vitamins and replacement pancreatic enzymes (Creon, Duphar) prescribed. Only three of the 11 subjects with cystic fibrosis were taking a multivitamin supplement that contained vitamin $A$ at the time of study.

Each participant completed a record of a seven day weighed food intake. During the final days of this period a three day stool collection was completed between carmine markers. The
Correspondence to: Professor Jackson.

Accepted 8 February 1990 
three day stool collection was weighed, pooled, and homogenised in deionised water to a smooth consistency before being stored at $-20^{\circ} \mathrm{C}$. The dietary record was coded and analysed using a computerised data base of food composition, Microdiet, for total fat and retinol content. ${ }^{9}$ A specimen of stool was analysed for total lipid by a modification of the method of van de Kamer et al. ${ }^{10}$ The retinol content of the stool was measured as described below.

EXTRACTION OF VITAMIN A FROM STOOL Specimens of stool were thawed, mixed thoroughly in a shaker, and $5 \mathrm{~g}$ of the sample was saponified with $1 \mathrm{~N}$ potassium hydroxide $(5 \mathrm{ml})$ in $90 \%$ ethanol and $10 \%$ distilled water containing $1 \%$ pyrogallol, at $60^{\circ} \mathrm{C}$ for 30 minutes. After cooling to room temperature, distilled water, $5 \mathrm{ml}$, was added, followed by hexane, $10 \mathrm{ml}$. The samples were mixed intermittently for one minute then centrifuged at $1000 \mathrm{~g}$ for 10 minutes. The top hexane layer was collected. The extraction procedure was repeated, with a further $10 \mathrm{ml}$ hexane. The hexane extracts were pooled and evaporated to dryness using a rotavapour at $40^{\circ} \mathrm{C}$. The dried extract was redissolved in $10 \mathrm{ml}$ methanol, and $100 \mu \mathrm{l}$ of this solution was used for injection into the HPLC.

\section{ANALYSIS OF RETINOL}

Retinol was separated by HPLC and analysed spectrophotometrically, using a Kratos solvent delivery system (Spectroflow 400) and a programmable absorbance detector (Spectroflow 783), Spectra Physics autosampler (SP 8780), and Spectra Physics programmable integrator (SP 4290). The stainless steel column was packed with silica (spherisorb ODS2, Jones
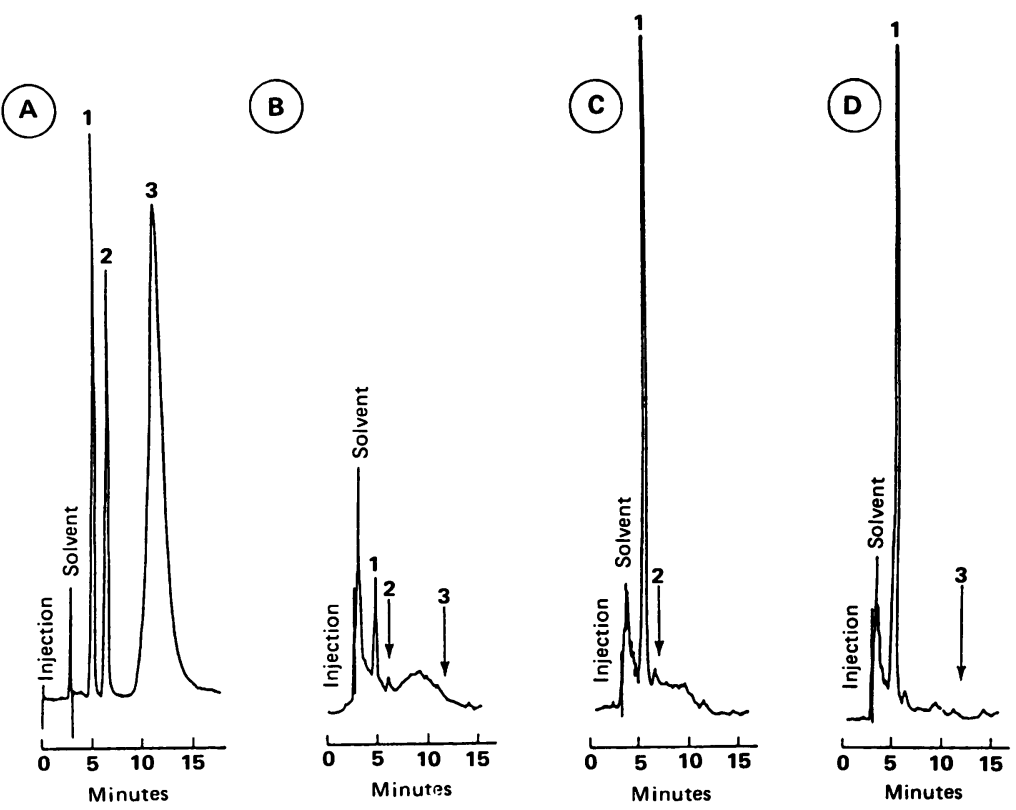

Figure 1 Analysis of sample of stool by HPLC after saponification for retinol. The chromatogram from the HPLC showed a series of peaks: 1 , retinol at 4.6 minutes; 2 , retinyl acetate at 6.4 minutes; 3 , retinol palmitate at 12 minutes. Trace A: chromatogram of standard compounds 1, 2, and 3. Trace B: chromatogram of a stool sample after saponification, without any added standard. Trace $C$ : chromatogram of stool sample with added retinol acetate. Trace D: chromatogram of stool sample with added retinol palmitate. For traces $C$ and $D$ no peak was detected at 6.4 or 12 minutes respectively.
Chromatography, Wales). A guard column, 2·0 $\mathrm{cm} \times 0.4 \mathrm{~mm}$, packed with pelicular OD silica, was attached to the primary column. The solvent system was HPLC grade methanol: water, $97 \cdot 5: 2 \cdot 5$. The methanol was obtained from Rathburn Chemicals Ltd, Scotland. Reaction grade hexane $\left(60-80^{\circ} \mathrm{C}\right.$ fraction from petroleum ether) was obtained from British Drug Houses as was the potassium hydroxide and pyrogallol. The standard compounds, all-trans retinol, all-trans retinyl acetate, and retinyl palmitate were obtained from Sigma.

For quantitation, $100 \mu \mathrm{l}$ of a solution containing a known amount of retinol in methanol was entered into the HPLC using the automatic injector, and eluted using a flow rate of $1 \mathrm{ml} /$ minute, with the detector set at 0.01 attenuation. Retinol emerged after the solvent front with a retention time of 4.9 minutes (fig $1 \mathrm{~A}$ ). The area under the peak at 4.9 minutes gave the amount of retinol in a sample. The precision of the HPLC instrument was determined by assaying 10 replicates of the same sample of retinol, which for a mean of $3.85 \mu \mathrm{g} / 100 \mathrm{ml}$ gave a coefficient of variation of $0.89 \%$. A standard curve was prepared using between 2.0 and 10 $\mu \mathrm{g} / \mathrm{ml}$ all-trans retinol in methanol. There was good separation of standard solutions of retinol, retinol acetate, and retinol palmitate with retentions of $4.9,6.4$, and 12 minutes respectively (fig 1A).

Saponified stool samples gave a peak at 4.9 minutes (fig 1B). When the absorption maximum was determined for this peak and compared with that for the synthetic all-trans retinol standard, there was no difference in the pattern of absorbance (fig 2). Known quantities of either retinol acetate or retinol palmitate were added to a sample before saponification. In each case, after extraction, there was a large peak at 4.9 minutes, with a loss of the peak at either 6.4 or 12 minutes, indicating virtual complete conversion of the retinol acetate and retinol palmitate to retinol (fig 1C and D). Some of the stool samples gave a small peak at 6.4 minutes, which persisted after hydrolysis, and therefore is unlikely to have been retinol acetate. The reproducibility of the method was determined by carrying out replicate measurements on stool samples with either a low or a high retinol content. For 10 replicates the means were 8.7 and $694 \mu \mathrm{g}$ retinol day with coefficients of variation of 15 and $10 \%$ respectively.

It is desirable where possible to use an internal standard, and in the past retinol acetate has been used for this purpose and was added after the stage of saponification. ${ }^{7}$ In our experience retinol added at this stage underwent appreciable saponification to free retinol and could not therefore be used as an internal standard. Attempts to identify a suitable internal standard, such as isomers of retinol, did not meet with success. Therefore, during the assay of retinol in the stools, four samples were run for each stool: in two of these samples a known amount of retinol $(5 \cdot 0 \mu \mathrm{g} / \mathrm{sample})$ was added. The amount of retinol in each stool was calculated on the assumption that the added retinol was affected in the same way as any retinol in the sample. For the 23 samples, the recovery of 


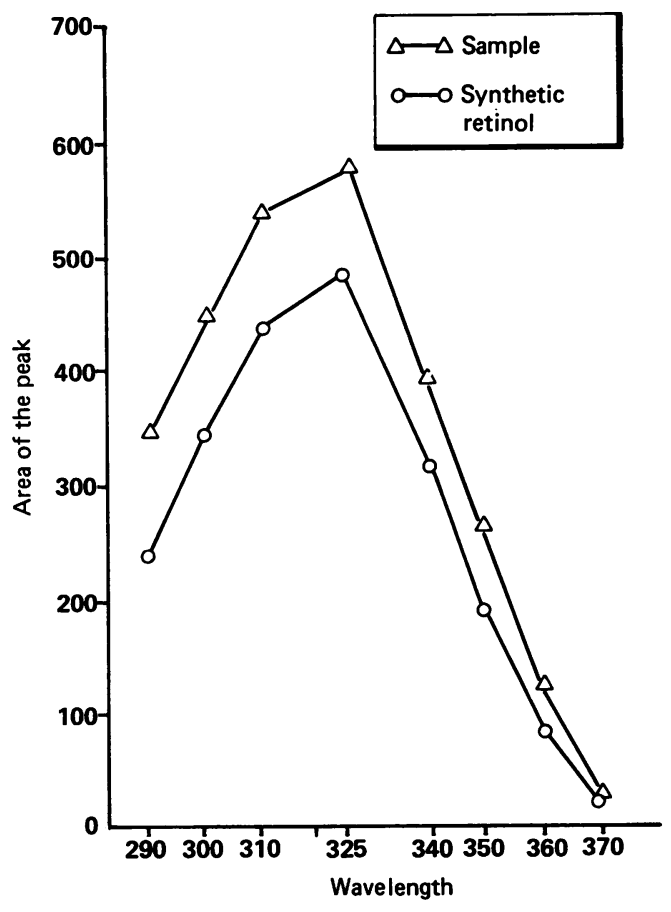

Figure 2 Analysis of sample of stool by HPLC after saponification and the peak at 4.6 minutes collected. The absorption spectrum of this peak was compared with that of synthetic retinol and the spectra for two peaks were found to be identical. The amount of retinol in a sample was calculated as the area under the peak, as compared with a standard.

retinol was $91 \%$ with the overall coefficient of variation for the recovery being $9 \%$.

ANALYSIS OF FAECAL FAT

The lipid content was determined in $20 \mathrm{~g}$ of homogenised stool, using SMA Gold Cap
(Wyeth) as a standard. The coefficient of variation was $5.9 \%$ for a sample giving a mean of $2 \cdot 4 \mathrm{~g}$ day.

\section{STATISTICAL ANALYSIS}

Significant differences were sought between the control group and the subjects with cystic fibrosis using the Wilcoxon rank sum test.

\section{Results}

The study was completed in 12 controls (seven females and five males) and 11 subjects with cystic fibrosis (seven females and four males). The controls were aged between 8 and 21 years and those with cystic fibrosis 8 to 24 years (table). The intakes of fat and retinol were not distributed normally. Although the subjects with cystic fibrosis tended to have a lower intake of fat, this did not reach significance, nor was there a significant difference in the intake of retinol. The faecal losses of fat were nearly three times as great in the subjects with cystic fibrosis as the controls, $\mathrm{p}<0.05$. The fat found in the stool relative to the intake was a median of $11.4 \%$ in those with cystic fibrosis, compared with $3.1 \%$ in the controls. The difference in the apparent absorption of fat, a median of $75 \mathrm{~g}$ for the controls and $60 \mathrm{~g}$ for those with cystic fibrosis, did not reach significance because of the wide range of variation in each group. The intake of retinol by the subjects with cystic fibrosis was not significantly different from the controls, but whereas the controls only excreted a median of $1.8 \%$ of the intake in the stool the subjects with cystic fibrosis lost $40 \%$; this is a highly significant difference, $\mathrm{p}<0.002$ (fig 3). Therefore, although the ratio of retinol to fat in the diet was not different between the two groups $(9 \cdot 2$ compared with $11 \cdot 8)$ there was a

Details of 12 controls and 11 subjects with cystic fibrosis. The dietary intake of fat and retinol was calculated, using food composition tables, based upon the weighed intake over seven days, on the assumption that carotene is equivalent to one sixth retinol equivalent. The faecal losses of fat and retinol were analysed in a three day collection of stool

\begin{tabular}{|c|c|c|c|c|c|c|c|c|}
\hline \multirow{2}{*}{$\begin{array}{l}\text { Subject } \\
\text { No }\end{array}$} & \multirow[t]{2}{*}{ Sex } & \multirow{2}{*}{$\begin{array}{l}\text { Age } \\
\text { (years) }\end{array}$} & \multicolumn{3}{|c|}{ Fat (g/day) } & \multicolumn{2}{|c|}{ Retinol ( $\mu g /$ day) } & \multirow[b]{2}{*}{ Out/In (\%) } \\
\hline & & & In & Out & Out/In (\%) & In & Out & \\
\hline $\begin{array}{r}1 \\
2 \\
3 \\
4 \\
5 \\
6 \\
7 \\
8 \\
9 \\
10 \\
11 \\
12\end{array}$ & $\begin{array}{l}\mathrm{F} \\
\mathrm{F} \\
\mathrm{F} \\
\mathrm{M} \\
\mathrm{F} \\
\mathrm{M} \\
\mathrm{F} \\
\mathrm{M} \\
\mathrm{F} \\
\mathrm{M} \\
\mathrm{M} \\
\mathrm{F}\end{array}$ & $\begin{array}{r}20 \\
21 \\
11 \\
12 \\
9 \\
21 \\
11 \\
9 \\
10 \\
12 \\
8 \\
9\end{array}$ & $\begin{array}{r}79 \\
62 \\
166 \\
55 \\
102 \\
55 \\
61 \\
76 \\
84 \\
78 \\
99 \\
70\end{array}$ & $\begin{array}{l}\text { Control } \\
3 \cdot 7 \\
4 \cdot 3 \\
1 \cdot 8 \\
2 \cdot 1 \\
5 \cdot 0 \\
5 \cdot 6 \\
1 \cdot 1 \\
2 \cdot 3 \\
1 \cdot 5 \\
2 \cdot 4 \\
2 \cdot 1 \\
1 \cdot 8\end{array}$ & $\begin{array}{r}4 \cdot 7 \\
6 \cdot 9 \\
1 \cdot 1 \\
3 \cdot 8 \\
4 \cdot 9 \\
10 \cdot 2 \\
1 \cdot 8 \\
3 \cdot 0 \\
1 \cdot 8 \\
3 \cdot 1 \\
2 \cdot 1 \\
2 \cdot 6\end{array}$ & $\begin{array}{r}122 \\
636 \\
1250 \\
556 \\
1280 \\
556 \\
2730 \\
502 \\
637 \\
647 \\
669 \\
897\end{array}$ & $\begin{array}{r}12 \\
31 \\
12 \\
15 \\
19 \\
13 \\
65 \\
8 \\
11 \\
10 \\
13 \\
7\end{array}$ & $\begin{array}{l}9 \cdot 8 \\
4.9 \\
1.0 \\
2.7 \\
1.5 \\
2.3 \\
2.4 \\
1.6 \\
1.7 \\
1.5 \\
1.9 \\
0.8\end{array}$ \\
\hline \multicolumn{3}{|c|}{ Median (range) } & $\begin{array}{l}77 \\
(55-166)\end{array}$ & $\begin{array}{l}2 \cdot 2 \\
(1 \cdot 1-5 \cdot 6)\end{array}$ & $3 \cdot 5$ & $\begin{array}{l}632 \\
(112-2733)\end{array}$ & $\begin{array}{c}12 \cdot 5 \\
(7-65)\end{array}$ & $1 \cdot 8$ \\
\hline $\begin{array}{r}1 \\
2 \\
3 \\
4 \\
5 \\
6 \\
7 \\
8 \\
9 \\
10 \\
11\end{array}$ & $\begin{array}{l}\mathbf{F} \\
M \\
M \\
M \\
F \\
F \\
F \\
F \\
M \\
F \\
F\end{array}$ & $\begin{array}{r}17 \\
10 \\
9 \\
10 \\
24 \\
13 \\
14 \\
9 \\
9 \\
8 \\
17\end{array}$ & $\begin{array}{rr} & S u b \\
61 & \\
78 & \\
54 & \\
43 & \\
117 & \\
111 & \\
54 & \\
76 & \\
70 & \\
41 & \\
87 & \end{array}$ & $\begin{array}{c}\text { cts with cys } \\
2.5 \\
1.4 \\
2.5 \\
4.3 \\
17.0 \\
3.4 \\
10.9 \\
9.8 \\
9.6 \\
15.4 \\
9.9\end{array}$ & $\begin{array}{c}\text { fibrosis } \\
4 \cdot 1 \\
1.8 \\
4 \cdot 6 \\
10 \cdot 0 \\
14 \cdot 5 \\
3 \cdot 1 \\
20 \cdot 2 \\
12.9 \\
13 \cdot 7 \\
35 \cdot 5 \\
11 \cdot 4\end{array}$ & $\begin{array}{c}173 \\
1368^{*} \\
25 \\
714 \\
708 \\
1308^{*} \\
1200 \\
1270 \\
285 \\
287 \\
1577^{*}\end{array}$ & $\begin{array}{r}22 \\
14 \\
14 \\
678 \\
501 \\
583 \\
137 \\
344 \\
154 \\
25 \\
726\end{array}$ & $\begin{array}{r}12 \cdot 7 \\
10 \cdot 0 \\
56 \cdot 0 \\
95 \cdot 0 \\
70 \cdot 8 \\
44 \cdot 6 \\
11 \cdot 4 \\
27 \cdot 0 \\
40 \cdot 0 \\
8 \cdot 7 \\
46 \cdot 0\end{array}$ \\
\hline \multicolumn{3}{|c|}{ Median (range) } & $\begin{array}{l}70 \\
(41-117)\end{array}$ & $\begin{array}{l}9 \cdot 6 \\
(1 \cdot 4-17)\end{array}$ & $11 \cdot 4$ & $\begin{array}{l}714 \\
(25-1577)\end{array}$ & $\begin{array}{l}154 \\
(14-726)\end{array}$ & $40 \cdot 0$ \\
\hline
\end{tabular}

Includes a supplement of vitamin A (retinol $750 \mu \mathrm{g} /$ day) taken as Ketovite liquid, $5 \mathrm{ml}$. 


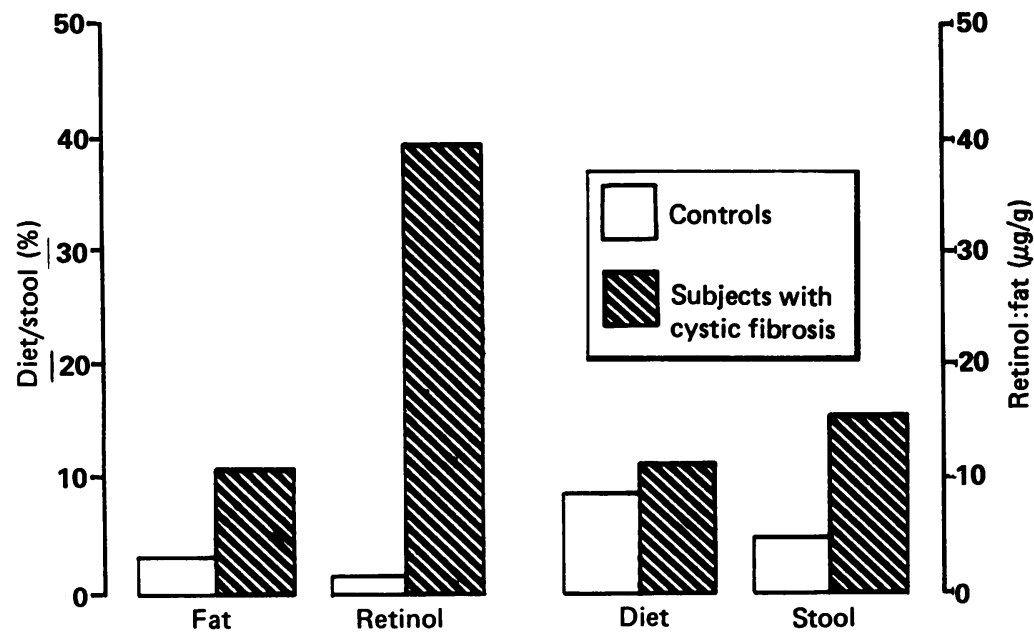

Figure 3 Dietary intake and the faecal excretion of fat and retinol in a group of subjects with cystic fibrosis compared with a group of control subjects. The percentage of dietary fat and retinol appearing in the stool was calculated, left panel, and the ratio of retinol to fat in the diet and the stool for the two groups of subjects, right panel.

significant difference in the ratio of retinol to fat in the stool $(5 \cdot 2$ compared with $16.0, \mathrm{p}<0.05)$ with subjects with cystic fibrosis losing disproportionately more retinol than fat. For all the variables measured there was a wide variation in both groups. In a number of the subjects with cystic fibrosis the losses of retinol and fat in the stool were not different to the controls, but in cystic fibrosis the range was much greater with some individuals having greatly raised faecal losses.

\section{Discussion}

There are very few reports in the literature on the retinol content of stool, because the methods adopted for analysis have been found to be unsatisfactory. ${ }^{8} 1112$ To our knowledge this is the first report in which HPLC has been adopted for the assay of retinol in stool. The approach that we have used is to determine the total retinol content by saponifying the sample so as to convert the retinol esters into the free retinol. The possibility that the esters in stool might not be completely hydrolysed was assessed by the addition of known amounts of retinol acetate and retinol palmitate to the stool. As shown in fig 1 , after saponification neither the acetate or the palmitate peak could be identified in the sample, implying that hydrolysis was complete. Although in some samples there was a peak that ran with retinol acetate, the size of the peak remained unchanged when the sample with added retinol acetate was saponified. When the synthetic retinol acetate and retinol palmitate were run after saponification, only a single peak of retinol could be identified. These results suggest that the saponification procedure effectively converted the esters of retinol into the free retinol.

Boron et al have suggested that the use of an antioxidant before saponification of liver samples had little effect upon recovery of retinol. ${ }^{13}$ However, we found that the addition of $1 \%$ pyrogallol gave slightly greater recovery of retinol from stool (data not shown). Hence pyrogallol was added as a routine to each sample before saponification. Extension of the duration of saponification from 30 to 45 minutes at $60^{\circ} \mathrm{C}$ resulted in a deterioration in recovery of $40 \%$. This finding contrasts with the observation of Senyk $e t$ al that with milk samples periods of saponification of 15 to 60 minutes made little difference to the recovery. ${ }^{\mathrm{I}}$ Spectral analysis confirmed the spectral identity of the peak at 4.9 minutes with that of retinol. It is difficult to prepare samples of stool that are completely homogenous, and the coefficient of variation for the measurement of between 10 and $15 \%$ was considered to be acceptable. Double extraction with hexane increased recovery from 85 to $91 \%$.

The subjects with cystic fibrosis in this study were all in a stable state at the time of the investigation. Their fat intake was not different from the controls, and although they had a mild degree of fat malabsorption, there was no difference in the apparent absorption of fat for the group as a whole, and they can be considered to have been under good control. Apparent absorption is defined as the intake minus the faecal losses. The assumption underlying the expression absorption is that faecal losses represent the residue of the dietary intake that is not absorbed, and ignore the possibility that faecal losses may include a component of endogenous losses. We know that there are endogenous losses that have not been quantified and feel that apparent absorption is a more correct term to use. The faecal loss of fat, median $2 \cdot 2 \mathrm{~g} /$ day in controls and $9.6 \mathrm{~g} /$ day in cystic fibrosis, are only a small proportion of the total intake, 3 and $11 \%$ respectively. The variation within the groups is sufficiently large that statistically it is not possible to demonstrate a difference for intake, faecal loss, or apparent absorption of fat on a group basis. It remains a possibility that biological differences of importance exist among individuals. For this reason we expressed both the intake and faecal loss of retinol as a ratio to the fat intake and loss. In this way we were able to draw out differences between groups.

All of the subjects with cystic fibrosis were prescribed a dietary supplement of vitamins. Three of the 11 were taking Ketovite liquid (Paines and Byrne) at the time of study, which provided $750 \mu \mathrm{g}$ retinol per day. The other eight were taking Ketovite tablets, which do not contain any vitamin A. Although there was no difference in the total intake of vitamin $A$ between the control children and those with cystic fibrosis, the supplement made an important contribution to the total intake of retinol in three of the 11 with cystic fibrosis. For cystic fibrosis an intake of approximately $2500 \mu \mathrm{g}$ of retinol may be recommended. None of the children in this study achieved these levels.

There was a pronounced and substantial difference in the faecal excretion of retinol between the two groups. A median of only $60 \%$ of the retinol was retained in cystic fibrosis compared with $98 \%$ in the controls. We have no basis for identifying the reason for this very large difference. It cannot be accounted for simply on the basis of fat malabsorption, because when one expresses the intake of retinol relative to that of fat, the results are similar for the two groups. However, the ratio is significantly increased in 
cystic fibrosis for excretion. It would appear that there might be a specific defect in the absorption of retinol, unrelated to that for fat. As retinol enters intestinal lymph as retinyl esters, the activity of the enzyme acylCoA:retinyl acyltransferase may be of importance for retinol absorption. However, Rasmussen et al were unable to identify any significant decrease in the activity of this enzyme from duodenal homogenates of children with cystic fibrosis. ${ }^{7}$ Nevertheless, in their small group of subjects the difference did approach significance, with wide variation within the group as a whole. The children with cystic fibrosis showed an abnormal absorption test in response to a single large oral dose of retinol.

The dietary analysis of retinol is not necessarily precise or specific, giving a value for retinol and for carotene. The table includes the dietary intake of carotene converted to retinol equivalents. It is possible that the effect we have observed might be attributable to differences in the intake of carotene and retinol between the two groups, but more detailed analysis of the data failed to demonstrate such a difference. There was no noticeable difference in the intake of either compound between the two groups. Only three of the subjects with cystic fibrosis were receiving a daily supplement of vitamin A. We have no reason to presume that the supplement is handled differently to the retinol in the food, and this cannot be used to provide a theoretical explanation for the differences observed.

We would conclude that the metabolic handling of retinol by the digestive tract in cystic fibrosis is different from normal. This cannot simply be accounted for by an association with fat malabsorption. It has been clearly demonstrated that there are difficulties in the trans- portation of retinol from the liver for use by the rest of the body in cystic fibrosis. ${ }^{3-5}$ It may be that the abnormality of absorption of retinol, and its mobilisation from the liver, represents a more general problem in the handling of retinol, and its transport across membranes in cystic fibrosis.

We express our appreciation for the help and assistance provided by Dr J Behn, Mrs S Bond, Dr C Rolles and Dr A Postle. Thi work was supported in part by the Wessex Medical School Trust with personal support from the Nestlé Nutrition Research Gran Programme (FA), the Cystic Fibrosis Research Trust (SW), and the Medical Research Council (JM)

1 Andersen DH. Cystic fibrosis of the pancreas, vitamin A deficiency, and bronchiectasis. F Pediatr 1939;15:763-71. 2 Petersen RA, Petersen VS, Robb RM. Vitamin A deficiency with xerophthalmia and night blindness in cystic fibrosis Am $\mathcal{F}$ Dis Child 1986;116:662-5.

3 Underwood BA, Denning CR. Blood and liver concentrations of vitamins $A$ and $E$ in children with cystic fibrosis of the pancreas. Pediatr Res 1972;6:26-31.

4 Smith FR, Underwood BA, Denning CR, Varma A Goodmen deW. Depressed plasma retinol binding protein levels in cystic fibrosis. F Lab Clin Med 1972:80:423-33.

5 JW Rothberg R. Zinc status and vitamin A transport in cystic fibrosis. Am $\mathcal{F}$ Clin Nutr 1978;31:638-44.

6 Shetty PS, Watrasicwicz KE, Jung RT, James WPT. Rapid Shetty PS, Watrasicwicz KE, Jung RT, James WPT. Rapid
turnover transport proteins: as an index of subclinical turnover transport proteins: as an index of subclin

7 Rasmussen $M$, Michalsen H, Lie SO, Nilsson A, Petersen LB, Norum KR. Intestinal retinol esterification and serum LB, Norum KR. Intestinal retinol esterification and serum retinol in children with cystic

8 Varma RN, Beaton GH. Quantitative aspects of the urinary and faecal excretion of radioactive metabolites of vitamin $A$ in the rat. Can $\mathcal{F}$ Physiol Pharmacol 1972;50:1026-37.

9 Paul AA, Southgate DAT. The composition of foods. 4th Ed. MRC Special Report No 297. London: HMSO, 1978.

10 Van de Kamer JH, Huinink H, Weyer HA. Rapid method for determination of fat in feces. 7 Biol Chem 1949;177: 347-55.

11 Roels OA, Trout M, Dujacquier R. Carotene balances on boys in Ruanda where vitamin A deficiency is prevalent. I Nutr 1958;65:115-27.

12 Sinclair AJ, Slattery W. Blood-collecting tube as a contamination source in vitamin E fluorometry. Clin Chem 1978;24: 2073-5.

13 Boron WA, Hupert J, Barch DH, et al. Effects of zinc deficiency on hepatic enzymes regulating vitamin A status. ciency on hepatic enzymes

14 Senyk GF, Gregory JF, Shipe WF. Modified fluorometric determination of vitamin A in milk. $\mathcal{J}$ Dairy Sci 1975;58: $558-60$. 